\title{
Analysis and Design of Test Bench for a Hexapod Robot
}

\author{
N. Sanchez ${ }^{1}$, H. D. Torres ${ }^{1}$, B. F. Contreras ${ }^{1}$, N. S. Coy $^{1}$, M. A. Jinete ${ }^{1}$ and R. D. Hernandez ${ }^{2, *}$ \\ ${ }^{1}$ Department of Mechatronics Engineering, Piloto University Bogotá, Colombia. \\ ${ }^{2}$ Department of Biomedical Engineering, Militar Nueva Granada University Bogotá, Colombia.
}

Received 26 February 2020; Accepted 10 October 2020

\begin{abstract}
This article presents the design of a test bench focused on the control of the legs of a hexapod robot, which allows studying the characteristics of the robot and obtaining some primary behaviors, whether mechanical, electrical or programming. In this way, a test bench structure is proposed to validate the control, performance and identification systems according to the efforts exerted by each of the components of the hexapod and also obtain a detailed view of their performance in structured environments and unstructured in order to correct its possible limitations so that in its implementation it can have coherence in response to the tasks that are posed. The results show the development of the test bench in which different types of legs were implemented which were considered the study of the mathematical model of direct kinematics and the selection of materials. For this reason, it is obtained that the best leg was the carbon fiber, since it has a very high safety coefficient, and it is very difficult for a fracture to occur when implementing it in the prototype, it is also chosen for its weight in comparison to other materials, since its characteristics have a lower structure density and high elasticity, it supports more axial loads than the other legs, even when subjected to intensive work. Finally, it is validated that the robot's performance in locomotion actions, basing this validation on the interpretation of the parameters captured by an optical sensor arranged for this task that generates the monitoring of movements in a controlled environment free of obstacles.
\end{abstract}

Keywords: Hexapod Robot, Tech Bench, Modelling control.

\section{Introduction}

Hexapod robots have a great advantage of movement in irregular terrain because they have a great capacity for adaptability, however these same conditions produce that the efforts made by each component are different and that in unforeseen situations failures that leave inactive or because serious problems occur in the robot as J. Ruiz says, he also comments that the legs in the animals fulfill functions of stability and locomotion, which gives them great adaptability in the environment [1]. For this reason, the need for the implementation of a test system for the legs of a hexapod robot is evidenced, with which the configuration of the most appropriate legs can be identified when interacting with the environment for which it was designed. According to $\mathrm{O}$. Ojeda Test benches are usually platforms specifically designed for the experimentation of a project in development [2]; These allow us to rigorously and repeatedly verify essential characteristics of each project, which makes them unique for a specific prototype. When making a hexapod robot, it is important to take into account the design of the legs, since they must be efficient for the task assigned to the robot, since depending on the terrain they can improve or decrease the performance of the prototype. Locomotion with legs can be a problem of interest to robotics, since the robot has to be statically and dynamically stable, the degree of difficulty in getting a hexapod robot to walk depends on the type of robot that is built. As he says in the article "Design

\footnotetext{
*E-mail address: ruben.hernandez@unimilitar.edu.co

ISSN: $1791-2377$ @ 2020 School of Science, IHU. All rights reserved.

doi:10.25103/jestr. 135.19
}

and construction of a hexapod robot" there are several projects of hexapod robots duly documented; However, some publications stand out for offering solutions to the different aspects that the problem of walking robots [3]. In addition, if the robot is required to walk autonomously through rough terrain overcoming obstacles that can unbalance it, it is necessary to adapt it with different algorithms that calculate and choose the best movement of the legs before the possible solutions, or generate an algorithm that allows it to take the most appropriate decision according to the dynamics of the terrain [4]. The maneuverability must be very high when making a hexapod robot, we must take into account the possible obstacles to overcome, which often leads to a compromise solution between size and ability to overcome obstacles, in the grip of the ground. This makes it necessary for the robot to have the necessary power so that the traction system can have an adequate grip on the ground, stability is a primary requirement, especially if one takes into account the level differences in the terrain where the robots can get to operate to perform the test bench it is necessary to have a dynamic model of the robot. Which allows to evaluate the behavior of the system and with the implementation of the obtained equations, it can be done in a simulation software not only for its physical behavior but also for the simulation of the image processing required for this dynamic. In this way, the article is divided as follows: first the selection of materials that were taken into account to perform the tests will be described, then the mathematical model of the hexapod robot's leg is illustrated and finally the methodology that It was developed for implementation. Finally, the results and conclusions are raised. 


\section{Materials Selection}

For the design criterion, the dimensions of the leg were selected, together with the choice of the parameter of values of a maximum height that represents what will be in the robot chassis. For a good selection of materials, you have to take into account the elasticity theory and the break criteria in addition to the Von Mises criterion as shown in the following articles where the tension that is proportional to the distortion energy in different materials [5] - [7] is analyzed. Specifically, four different forms of legs have been designed and each of them has been statically simulated using the finite element method (FMA or MEF). Each leg has been simulated with different materials: ABS plastic, Aluminum, Nylon and Carbon fiber. From these simulations, the safety coefficients of each leg in the most unfavorable situation have been extracted, as can be seen in Figure 1, the different legs to be studied are shown. Dynamic simulations have been performed (with the leg in motion) in which it is checked in which cases the most unfavorable situation that can fracture the leg.

These materials have been chosen to rise due to their mechanical properties. In the simulation, isotropic materials have been considered, which refer to an elastic constant that each of the physically measurable parameters characterizes the elastic behavior of a deformable solid. Sometimes the term elastic constant is also used to refer to the stiffness coefficients of an elastic bar or plate [8] - [10]. You have to Young's modulus, compressibility module and Poisson's coefficient. To comply with the transverse elastic modulus relationship, through equation 1.

$$
G=\frac{E}{(2(1+V))}
$$

Where:

- $\quad$ E is Young's module

- $\mathrm{G}$ is the transverse elastic module

- $\quad \mathrm{V}$ is the poisson coefficient

Young's module and the transverse module of each chosen material can be seen in Table 1 .

Table 1. Selected design parameters

\begin{tabular}{c|c|c}
\hline Materials & E(Gpa) & G (Gpa) \\
\hline Nylon & 2,9 & 1,1 \\
ABS & 2,3 & 0,8 \\
Carbon fiber & 70 & 31,8 \\
PVC & 2,4 & 4,1 \\
Aluminum & 69 & 25 \\
\hline
\end{tabular}

However, the failure mechanisms depend on the microscopic structure of the material and the shape of its atomic bonds. To predict the failure of materials under static loads (static load is considered to be one that does not vary in magnitude or direction in time) and in order to perform the design of the test bench well, several theories have been developed for groups of materials, based on in experimental observations as shown in table 2 [11] - [13]

Table 2. Fault theories

\begin{tabular}{l|l}
\hline \multicolumn{1}{c|}{ Ductile Material } & \multicolumn{1}{c}{ Fragile Material } \\
\hline $\begin{array}{l}\text { Theory of maximum shear stress } \\
\text { Tresca Theory (MSS) }\end{array}$ & $\begin{array}{l}\text { Theory of maximum } \\
\text { normal effort } \\
\text { Rankine theory (MNS) } \\
\text { Coulomb Mohr Fragil } \\
\text { theory (BCM) }\end{array}$ \\
$\begin{array}{l}\text { Distortion energy theory } \\
\text { Von Misses Theory (DE) }\end{array}$ &
\end{tabular}

Theory of internal friction (Coulomb) Mohr Ductil (IFT)

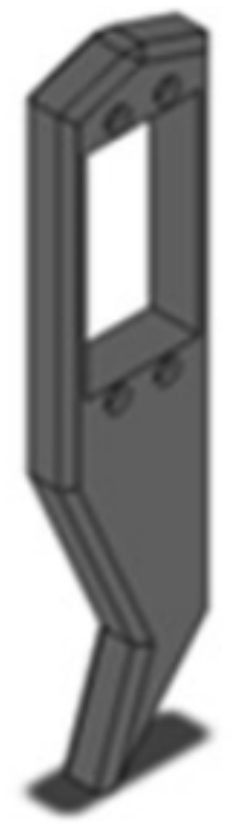

a)

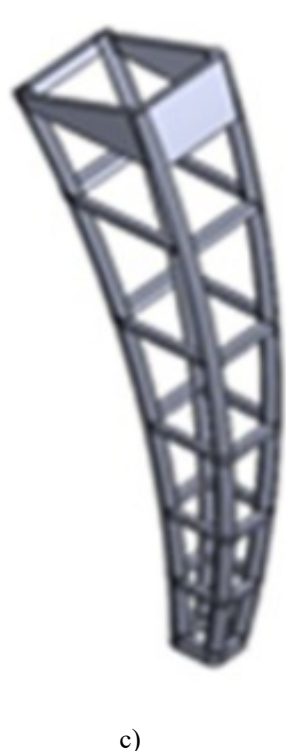

c)

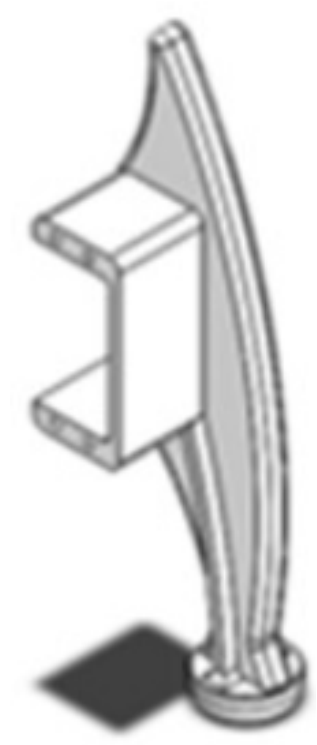

b)

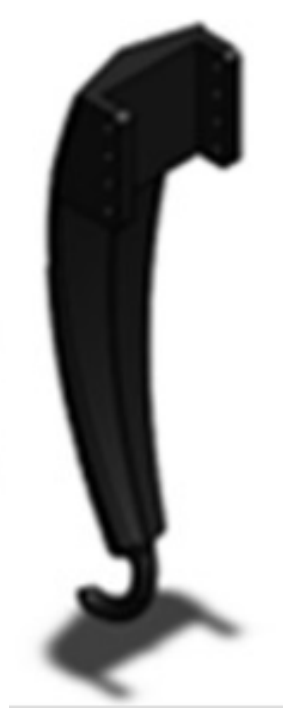

d)
Fig 1. Leg designs with different materials, a) Aluminum, b) Nylon, c) ABS and d) Carbon Fiber

At the time of testing the number one legs as shown in Figure 1, it produces a failure when the absolute maximum shear stress on the part is equal to or greater than the absolute maximum shear stress of a specimen subjected to a stress test at the time that fluence occurs, as shown in Figure 2.

In order to analyze the suitability of the leg shape in certain areas, a test bench has been built with an elastic band to simulate the legs in different areas such as: soil (soil), oil and gravel as shown in the Figure 3. From the results obtained for each type of terrain, and taking into account the frequency parameters, the ideal leg for each type of terrain has been chosen. 


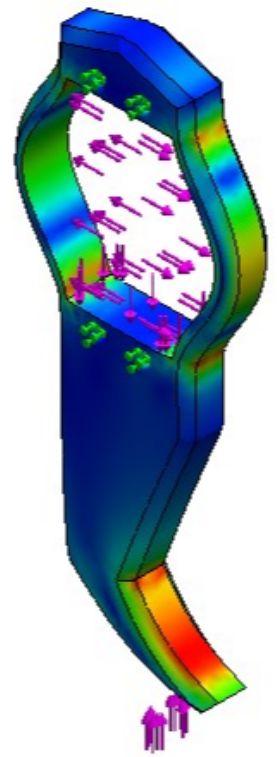

Fig 2. Failure analysis of leg design 1.
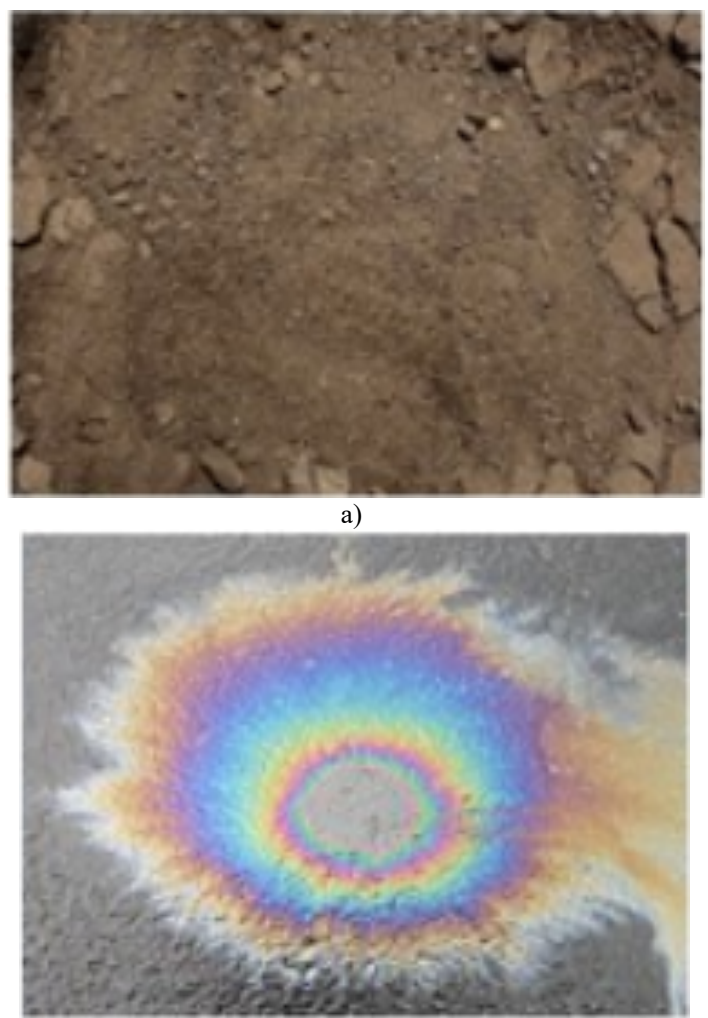

b)

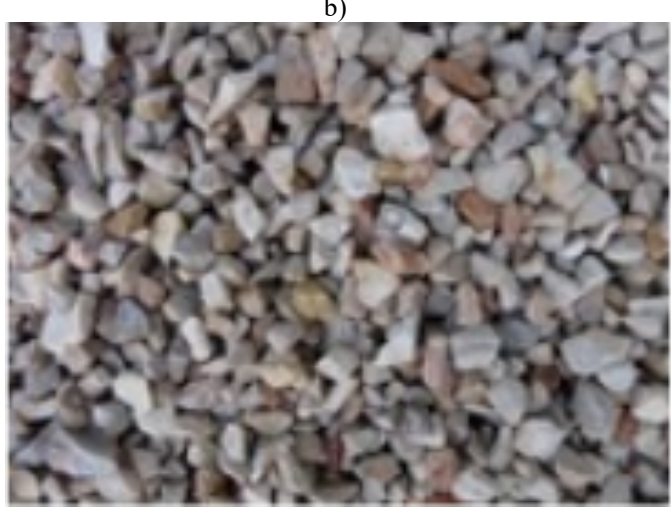

c)

Fig 3. Land types a) Earth, b)Oil and c)Gravel
The finite element method (FEA), is a numerical method for the solution of engineering problems, today commonly used for the resolution of problems that involve a high degree of complexity, of applied mathematics as well as the mathematical mathematics, since the great Most of the problems that arise in these areas commonly involve complex geometries, undistributed loads and determination of material properties, so it is generally not possible to obtain any analytical solution directly from mathematical expressions [3] $-[6]$.

\section{Mathematical model}

The mathematical analysis begins with the kinematic and dynamic model of the robot, in this article we present the dynamic modeling for the implementation in the test bench; More information on the kinematic model of different hexapod robots [14] - [34] is found in the following citations, which have as final formulas the matrix of transformation of link $\mathrm{i}$ for i-1 by implementing Denavit Hartengberg parameters.

$T_{i}^{i-1}=\left[\begin{array}{cccc}\cos \theta_{i} & -\sin \theta_{i} \cos \alpha_{i} & \sin \theta_{i} \sin \alpha_{i} & L_{i} \cos \theta_{i} \\ \sin \theta_{i} & \cos \theta_{i} \cos \alpha_{i} & -\cos \theta_{i} \sin \alpha_{i} & L_{i} \sin \theta_{i} \\ 0 & \sin \alpha_{i} & \cos \alpha_{i} & d_{i} \\ 0 & 0 & 0 & 1\end{array}\right]$

The transformation matrix is calculated from the following series of transformations, as shown in table 3 .

Table 3. Product of calculated matrices

\begin{tabular}{c|c}
\hline Parameters & \multirow{2}{*}{ Taxa } \\
Translation $\left(d_{i}\right)$ along the axis $z_{i-1}$ & $\boldsymbol{T}_{\text {base }}^{\text {coxa }} \boldsymbol{x} \boldsymbol{x} \boldsymbol{T}_{\text {tibia }}^{\text {fermur }} \boldsymbol{x} \boldsymbol{T}_{\boldsymbol{b a s e}}^{\text {tibia }}$ \\
Rotation $\left(\theta_{i}\right)$ around the axis $z_{i-1}$ & \\
Translation $\left(L_{i}\right)$ along the axis $x_{i-1}$ & \\
Rotation $\left(\alpha_{i}\right)$ around the axis $x_{i-1}$ & \\
\hline
\end{tabular}

Having the kinematics, the finite element method was defined to perform the simulation of different leg morphologies, and different materials, to subsequently apply the criteria for material resistance failure (von Mises, Tresca) [9] - [11] as shown in table 4, thus establishing a systematic method for the selection of the optimum leg in a specific terrain subject to certain loads.

Table 4. Design Factors where yp / $\mathrm{N}$ is the safety factor

\begin{tabular}{c|c|c}
\hline Tresca & Von misses & Rankine \\
\hline$\sqrt{\sigma^{2}+4 \tau^{2}} \leq \frac{\sigma_{y p}}{N}$ & $\sqrt{\sigma^{2}+3 \tau^{2}} \leq \frac{\sigma_{y p}}{N}$ & $\frac{\sigma}{2} \sqrt{\frac{\sigma^{2}}{4}+\tau^{2}} \leq \frac{\sigma_{y p}}{N}$
\end{tabular}

A dynamic modeling has been obtained in which different models have been established from greater to less complex. In addition, the study of the contribution of each type of internal effort of the leg (flexion, shear, normal) in total deformation was implemented. These results have been compared with the results obtained by FEA through statistical analysis of non-linear regressions and by experimentation with the test bench. Initially, the kinematics of an individual leg will be considered considering that the other legs do not influence its movement. Bearing in mind that sliding is not considered either in the transverse or longitudinal direction. This hypothesis, is valid in the ways of march like the 
alternate tripod that is in which this article is going to center. The finite element method was used as shown in Figure 4.

You can see the module of the constant speed, corresponding to the section of the link, in which the axis point describes the joints. The mathematical model allows to know the characteristics for each of the elements and for the

ABS
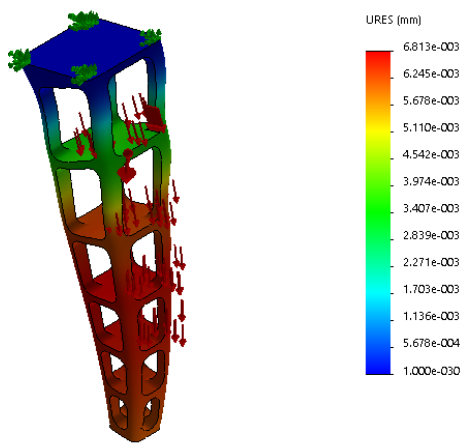

Nylon

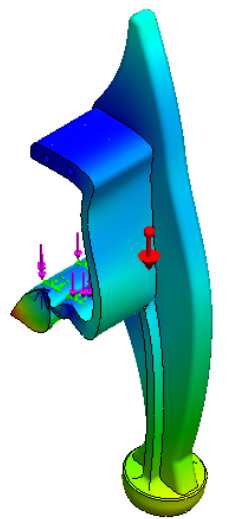

URES (mm)

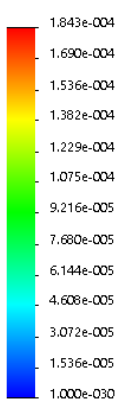

Fig 4. Material Analysis

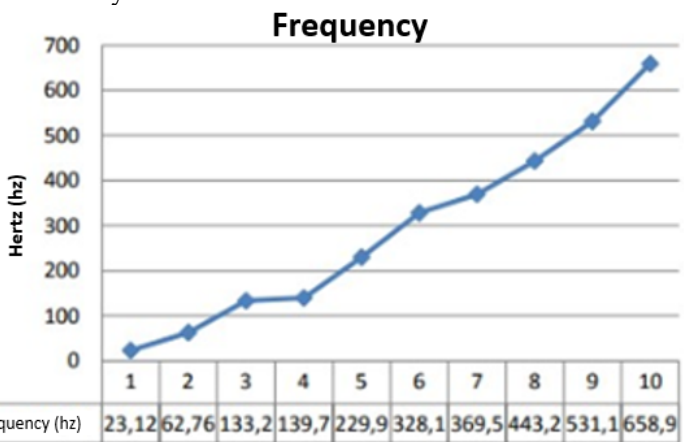

Fig. 5. Vibration modes according to position

The inverted pendulum model (also called SLIP) was also implemented to analyze the leg. The Slip model is implemented for the analysis of the legs of animals such as cockroaches, spiders, crabs, among others. This model is shown in Figure 6.

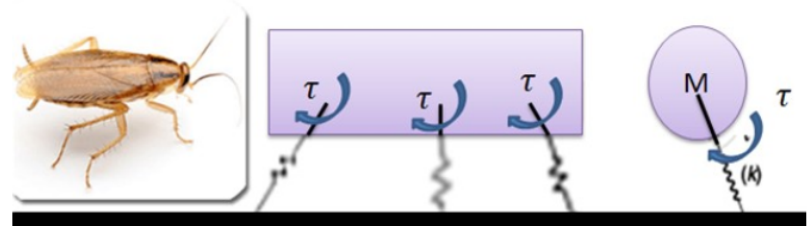

Fig. 6. Kinematic model of the cockroach whole of everything, both for the individual leg. If the robot moves all the legs at the same time and without offset the dynamic model coincides with that of the individual leg, if the mode of travel is the alternate tripod, it has been shown that the discrete line is part of the curve described by the leg individual, as shown in Figure 5.

\section{Aluminum}

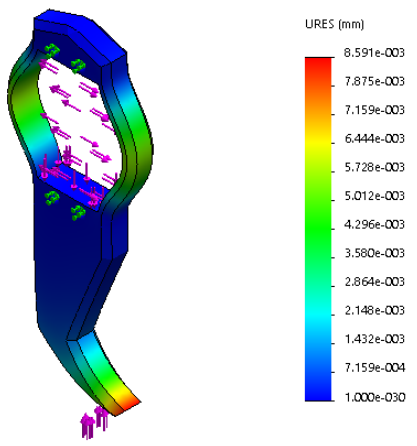

\section{Carbon fiber}

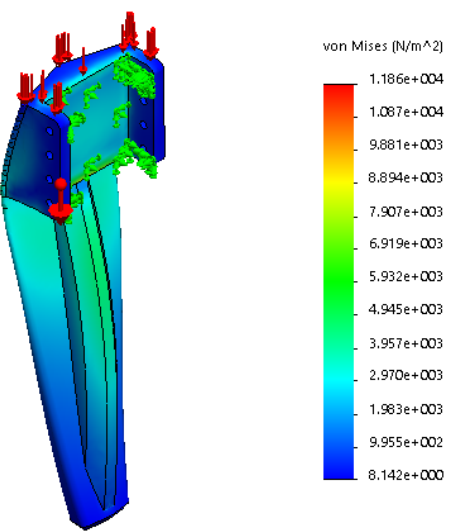

According to the image a spring mass system is obtained, it is that $\mathrm{x}$ is the position, the current system has a mass with only two forces in the vertical direction: the force exerted by the spring and the force of the shock absorber. For small displacements with respect to its natural length, the force exerted by the spring on the mass is given by:

$F=-k(x-10)$

Figure 7 shows the plane in $2 \mathrm{~d}$ which shows the theta angle and its length against the length of the test bench.

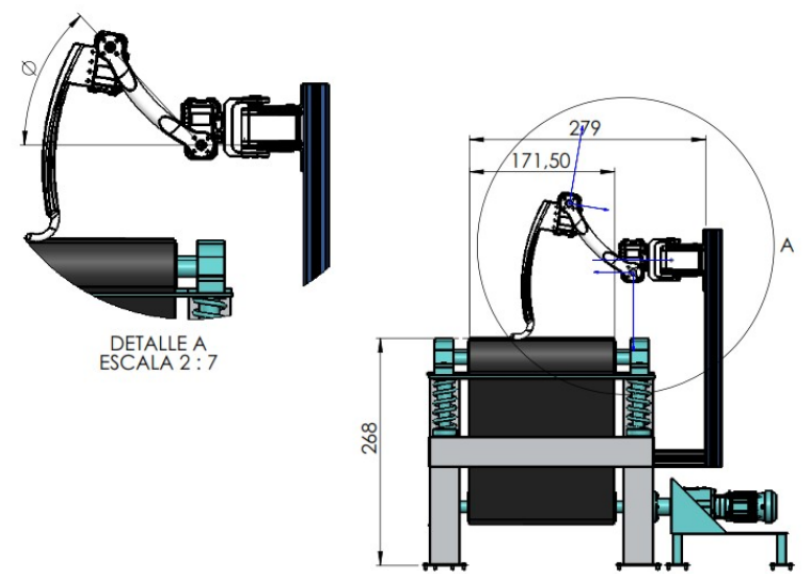

Fig 7. 2d plane corresponding to the analysis of the leg. 
Thus, Newton's equation for mass $\mathrm{M}$ is given by:

$M \ddot{x}=-k(x-10)-c \dot{x}$

After obtaining the mechanical model, the SLIP model was implemented, it differs during the movement of the support phase and flight phase as shown in Figure 6. For this, the flight phase is taken into account: when considering all the mass concentrated in One point, the equations of the flight phase, in Cartesian coordinates, are as follows:

$\{\ddot{x}=0$

$\{\ddot{y}=-g$

The body will follow a fixed point. Support phase: the teta variable in the Cartesian coordinates $\mathrm{x}$ and $\mathrm{y}$ can be considered as independent variables as shown in Figure 8.

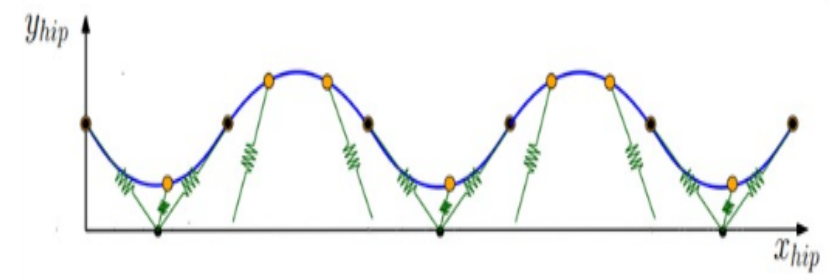

Fig. 8. Analysis of the support variables in each of the phases.

\section{Methodology}

In order to carry out experiments with different shapes and materials of legs, a test bench has been built with the characteristics of supporting the mechanisms of a hexapod leg that has 3 degrees of freedom, this design consists of a conveyor belt that contains several sensors and an aluminum bracket where the hexapod leg will be installed. The design of the test bench can be seen in Figure 9.

To simplify the experiments, the legs whose rotation axis does not coincide with the center of it have been chosen, so that they do not resemble both wheels, but legs. Therefore, leg 4 has been selected as shown in Figure 10 and the analysis has been performed as shown in Table 5 .

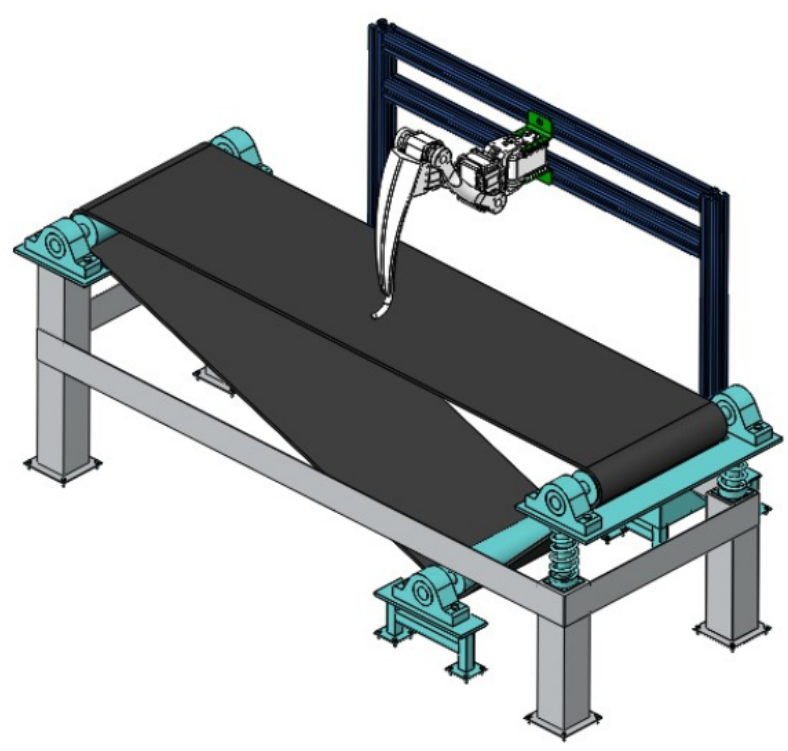

Fig. 9. Design of the test bench of one leg.

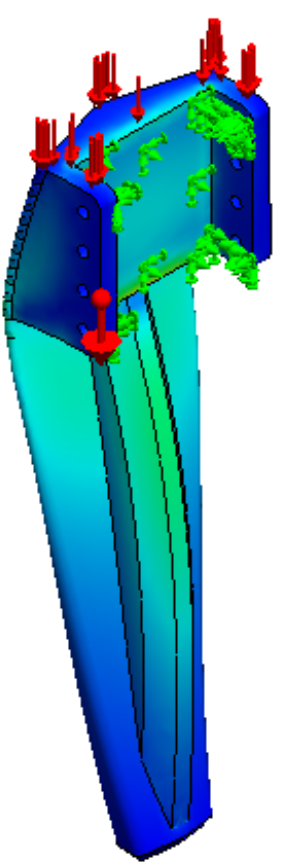

von Mises $\left(\mathrm{N} / \mathrm{m}^{\wedge} 2\right)$

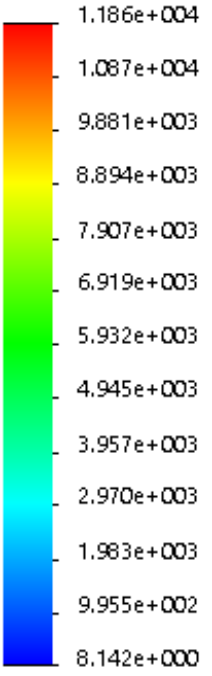

Fig. 10. Analysis of a leg in carbon fiber

Table 5. Comparison of different types of legs according to load analysis

\begin{tabular}{l|l|l|l}
\hline Model Posed & Material & Static analysis & $\begin{array}{c}\text { In accordance with the subjected loads } \\
\text { to which the leg works, a static analysis } \\
\text { study was carried out }\end{array}$ \\
\hline 1 & Aluminum & $\begin{array}{l}\text { It is concluded that the leg tends to } \\
\text { fracture in the thin parts of the lower } \\
\text { design since it is too weak to support the } \\
\text { weight of the hexapod. }\end{array}$ \\
\hline
\end{tabular}




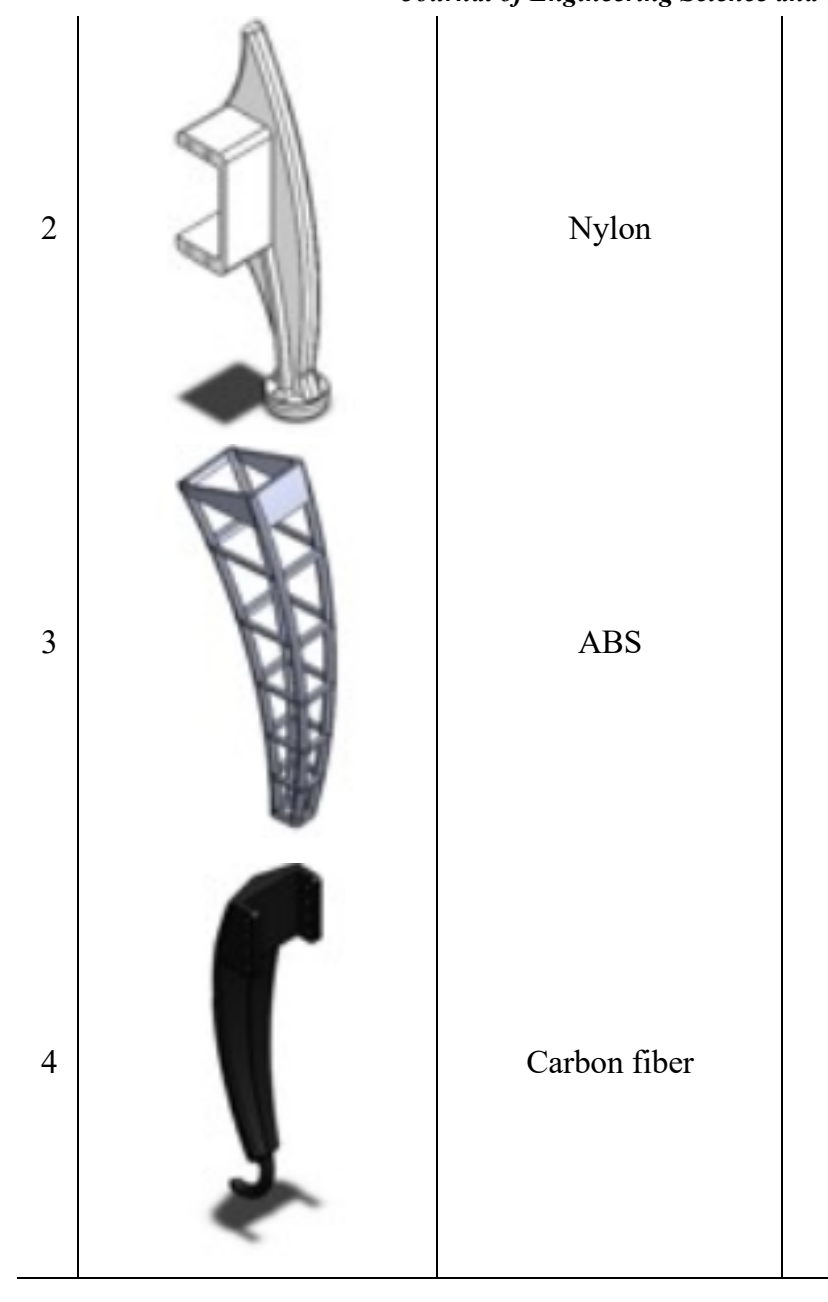

\section{Results}

The analysis of loads in each of the materials by means of the application of finite elements has allowed the determination of the safety coefficients for four proposed legs, the carbon fiber and the aluminum being the materials with the highest safety coefficients in the set of the four legs. The construction of a test bench has allowed to generate tests with the different legs in variable terrain. In Figure 1, the aluminum number leg is fractured in the lower part since the design is very weak and thin to support the weight of the hexapod. The second leg of nylon material tends to fracture in the support due to the change in geometry due to the concentration of stresses. The third leg in ABS is influenced at the moment of supporting the weight of the structure. In this way, the best design is the leg 4 in fiberglass material since when applying the loads of the body weight all the forces are distributed over the area of the leg and thus it does not have to generate any fracture. However, the most unfavorable situation of the leg is the change in the geometry of the support since being so thin and not having the appropriate stress concentrator tends to fracture. Finally, the graphs of different modes of movement are obtained in the test bench of the final leg from the displacement observing the frequency and the number of series that executed the action. As seen in Figure 11.

As it can be seen, the different ranges are shown in the graphs where the mechanism should not work since it produces large deformations when entering resonance, this type of vibrations should be avoided. As for the values of the modes in the different positions, it is observed that there is a great similarity, this is because the vibration modes take into account the properties of the material and the geometry not so much of the position in which find. The deformations that the structure undergoes in its most critical positions are small enough to consider that there are errors in the positioning of the end of the robot (maximum values of $0.025 \mathrm{~mm}$ have been obtained). It is necessary to comment that, the possible slack that the mechanism may have in its joints is not taken into account, this slack may have a different behavior between the actual mechanism and the results obtained. It has been observed that the structure does not suffer buckling under the same loading conditions with maximum travel values of $1.0055 \mathrm{~mm}$.
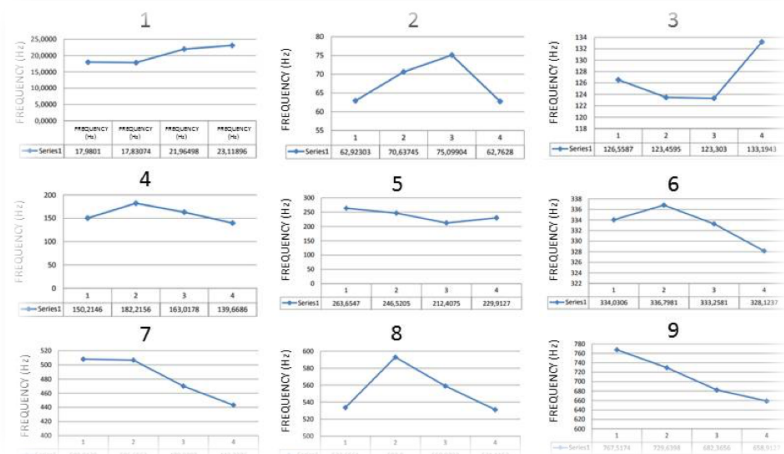

Fig 11. Gait analysis of the hexapod robot's leg 


\section{Acknowledgement}

The authors are grateful to the Pilot University and the Nueva Granada Military University.
This is an Open Access article distributed under the terms of the Creative Commons Attribution License

\section{References}

[1] J. Ruiz, "Diseño, construcción y control de un robot hexápodo", Univ. Nac. Autónoma México, pp. 1-103, 2014.

[2] Os.Ojeda, "Prueba y caracterización de mateirales", n.o May, 2015.

[3] D. Ancira, J. Betancourt, E. López, H. Martínez, y F. Ramírez, "Diseño y construcción de un robot hexápodo" Memorias Del Xvi Congr. Int. Anu. La Somim, pp. 1-10, 2011.

[4] R. Moreno Garcia, "Diseño y Simulación de un Algoritmo para el Control de un Robot Modular tipo Cadena / Design and Simulation of an Algorithm to Control a Chain Type Modular Robot”, p. 111, 2010.

[5] O. P. E.Salazar, "Diseño y construcción de un robot terrestre que sirva de platafor- ma para desarrollo de investigaciones en el área de robótica móvil en ambientes abiertos y cerrados", 2014.

[6] J. J. Camara, "Modelado Y Análisis De Un Brazo Mecánico”, Univ. Carlos III Madrid Esc. Politécnica Super., p. 160, 2010.

[7] M. Reich, "Minerales isótropos y anisótropos".

[8] T. P. Mecánicas et al., "Tema 5. propiedades mecánicas”.

[9] J. P. Botello , "Jorge Pirelli Botello", pp. 1-59.

[10]A. De Castro, "Teorías de falla bajo cargas estáticas", Rev. Cuba. Ing., pp. 1-11, 2014

[11] Supertronic SA, "Tabla De Propiedades Del Plastico Abs", p. 1, 2014.

[12]A. Jiménez Pézer Mitre, “Análisis y optimización con interacción de Dummy, de la carrocería del automóvil "Tu bolare SAND CAR" de Tecnoidea SA de CV, en impacto frontal empleando el método de elementos finitos en ALGOR FEA, mediante la simulación de eventos mecánicos", pp. 19-52, 2004.

[13]A. Cardona y V. Fachinotti, "Introducción al Método de los Elementos Finitos", 2014.

[14]D. García Jiménez, Universidad Complutense de Madrid Universidad Complutense de Madrid. 2009.

[15] Y. Zhai et al., "Gait planning for a multi-motion mode wheel-legged hexapod robot", 2016 IEEE Int. Conf. Robot. Biomimetics, ROBIO 2016, pp. 449-454, 2017.

[16]P. Arena, P. Furia, L. Patané, y M. Pollino, "Fly-inspired sensory feedback in a reaction-diffusion neural system for locomotion control in a hexapod robot", Proc. Int. Jt. Conf. Neural Networks, vol. 2015-Septe, pp. 0-7, 2015.

[17] S. Manoiu-Olaru y M. Nitulescu, "Locomotion strategies over obstacles for a hexapod robot using Matlab", 2013 17th Int. Conf. Syst. Theory, Control Comput. ICSTCC 2013; Jt. Conf. SINTES 2013, SACCS 2013, SIMSIS 2013 - Proc., pp. 325-330, 2013.

[18]M. Nitulescu et al., "«Designing the Legs of a Hexapod Robot", Proc. - IEEE Int. Conf. Robot. Autom., vol. 3, n.o December, p. $2015,2010$.

[19]A. Manglik, K. Gupta, y S. Bhanot, "Adaptive gait generation for hexapod robot using Genetic Algorithm”, 2016 IEEE 1st Int. Conf. Power Electron. Intell. Control Energy Syst., pp. 1-6, 2016.

[20]J. Ollervides, J. Orrante-Sakanassi, V. Santibanez, y A. Dzul, "Navigation Control System of Walking Hexapod Robot", 2012
IEEE Ninth Electron. Robot. Automot. Mech. Conf., pp. 60-65, 2012.

[21] S. Manoiu-Olaru, M. Nitulescu, y D. Popescu, "Motion analysis of a robot using a dedicated Matlab interface", 2014 18th Int. Conf. Syst. Theory, Control Comput. ICSTCC 2014, n.o 1, pp. 562-567, 2014.

[22]A. Roennau, G. Heppner, M. Nowicki, J. M. Zoellner, y R. Dillmann, "Reactive posture behaviors for stable legged locomotion over steep inclines and large obstacles", IEEE Int. Conf. Intell. Robot. Syst., n.o Iros, pp. 4888-4894, 2014.

[23] M. Travers, A. Ansari, y H. Choset, "A dynamical systems approach to obstacle navigation for a series-elastic hexapod robot", 2016 IEEE 55th Conf. Decis. Control. CDC 2016, n.o Cdc, pp. 5152$5157,2016$.

[24] G. Zhang, G. Yu, y Y. Bo, "Hexagonal hexapod robot foot-modeled dynamics simulation analysis", Proc. 2013 2nd Int. Conf. Meas. Inf. Control. ICMIC 2013, vol. 2, pp. 1107-1110, 2013.

[25] OG. Zhong, L. Chen, Z. Jiao, J. Li, y H. Deng, "Locomotion Control and Gait Planning of a Novel Hexapod Robot Using Biomimetic Neurons", IEEE Trans. Control Syst. Technol., pp. 1-13, 2017.

[26] Y. C. Chou, W. S. Yu, K. J. Huang, y P. C. Lin, "Bio-inspired step crossing algorithm for a hexapod robot", IEEE Int. Conf. Intell. Robot. Syst., pp. 1493-1498, 2011.

[27]A. A. M. Faudzi, G. Endo, S. Kurumaya, y K. Suzumori, "Longlegged Hexapod Giacometti Robot using Thin Soft McKibben Actuator“, IEEE Robot. Autom. Lett., vol. 3766, n.o c, pp. 1-1, 2017.

[28]E. Aggelopoulou, S. Member, y G. Rekleitis, "Optimal Leg Sequence Selection for an Underwater Hexapod Robot in the Presence of Slopes and External Forces", pp. 340-345, 2017.

[29] E. Gorrostieta y E. V. Soto, "Algoritmo Difuso de Locomoción Libre para un Robot Caminante de Seis Patas", Comput. y Sist., vol. 11, n.o 3, pp. 260-287, 2008.

[30]L. Bai, Z.-F. Dong, y X.-S. Ge, "The closed-loop kinematics modeling and numerical calculation of the parallel hexapod robot in space", Adv. Mech. Eng., vol. 9, n.o 2, p. 168781401668884 , 2017.

[31]D. Khudher y R. Powell, "Quadratic programming for inverse kinematics control of a hexapod robot with inequality constraints", Proc. 2016 Int. Conf. Robot. Curr. Trends Futur. Challenges, pp. 1$5,2017$.

[32]A. Akhlaq, J. Ahmad, y A. Umber, "Biologically inspired selfreconfigurable hexapod with adaptive locomotion", 16th Int. Power Electron. Motion Control Conf. Expo. PEMC 2014, pp. 432-438, 2014.

[33] Y.-C. Chou, K.-J. Huang, W.-S. Yu, y P.-C. Lin, "Model-Based Development of Leaping in a Hexapod Robot", Ieee Trans. Robot., vol. 31, n.o 1, pp. 40-54, 2015.

[34]E. Knoop, A. Conn, y J. Rossiter, "VAM: hypocycloid mechanism for efficient bio-inspired robotic gaits", IEEE Robot. Autom. Lett., vol. 2, n.o 2, pp. 1055-1061, 2017. 